\title{
How Activism Features in the Career Lives of Four Generations of Canadian Nurses
}

\author{
Judith A. MacDonnell, PhD, RN' and \\ Ellen Buck-McFadyen, $\mathrm{MScN}, \mathrm{RN}^{2}$
}

\begin{abstract}
Recent nursing research using a critical feminist lens challenges the prevailing view of political inertia in nursing. This comparative life history study using a critical feminist lens explores the relevance of activism with four generations of Canadian nurses. Purposeful sampling of Ontario nurses resulted in 40 participants who were diverse in terms of generation, practice setting, and activist practice. Interviews and focus groups were completed with the sample of Ontario registered nurses or undergraduate and graduate nursing students: 8 Generation X, 9 Generation Y (Millennials), 20 Boomers, and 3 Overboomers. Factors such as professional norms and personal and organizational supports shaped contradictory nursing activist identities, practices, and impacts. Gendered norms, organizational dynamics, and the political landscape influenced the meanings nurses attributed to critical incidents and influences that prompted activism inside and outside the workplace, shaping the transformative potential of nursing. Despite its limitations, the study has implications for creating professional and organizational supports for consideration of health politics and policy, and spaces for dialogue to support practice and research aligned with social justice goals.
\end{abstract}

\section{Keywords}

political action, health-care reform, advocacy, gender, generation, activism

Political activism is an important aspect of current Canadian nursing practice, yet little is known about how nurses experience and understand their own political activism (Avolio, 2014; MacDonnell, 2011). Throughout the history of the profession, registered nurses (RNs) have advocated individually and collectively for health and social reform. The World Health Organization and the Canadian Public Health Association (1986) suggest that health professionals play a vital role in promoting health and social justice through political action and policy work (Smith, Jacobson, \& Yiu, 2008). In this article, we report on a qualitative exploratory study of nursing activism in Ontario, Canada. The purpose of this study is to explore critical influences that shape meanings, practices, and impacts of nursing activism.

\section{Background}

Canada has a publically funded health-care system. National standards for health care are laid out in the Canada Health Act, under which provinces and territories organize and administer health care that ensures all Canadian residents have access to hospital and physician services free of charge (Government of Canada, 2016). In the province of Ontario, as in much of Canada, entry to practice for RNs requires an undergraduate baccalaureate nursing degree. When this policy was implemented in 2005, nurses with diplomas were grandfathered. In Ontario, there are diverse baccalaureate nursing programs including 4-year universitycollege collaborations, 2-year accelerated programs, post-RN programs, and a program for internationally educated nurses. Canadian nursing practice is informed by Primary Health Care (Canadian Nurses Association, 2005) that aims to promote health and prevent disease through attention to the broad social determinants of

\footnotetext{
'York University, Toronto, ON, Canada

${ }^{2}$ Trent University, Peterborough, ON, Canada
}

Corresponding Author:

Judith A. MacDonnell, York University, 4700 Keele Street, HNES Building, 3rd Floor, Toronto, ON M3J IP3, Canada.

Email: jmacdonn@yorku.ca 
health, accessibility, and public participation. Current Canadian nursing programs reflect Canadian Standards of Practice for Community Health Nurses (Community Health Nurses of Canada, 2011) in which health promotion for individuals, groups, communities, populations, and society includes political action and policy advocacy at micro, meso, and macro levels to work toward health equity for marginalized and vulnerable groups (Smith et al., 2008).

Recent scholarship on nurses' political practice reveals a discourse of political inertia and calls for innovative educational strategies to further develop nurses' policy and leadership skills, especially in the legislative arena (Avolio, 2014; Carnegie \& Kiger, 2009; D'Antonio, Connolly, Mann Wall, Whelan, \& Fairman, 2010; Montalvo, 2015; Spenceley, Reutter, \& Allen, 2006; Vandenhouten, Malakar, Kubsch, Block, \& Gallagher-Lepak, 2011). A critical feminist lens accounts for the relevance of gender and its intersections with other dynamics of power, such as racialization, in relation to the historical, social, cultural, economic, and political contexts that shape nursing and health. Nurse scholars who use a critical feminist lens offer a counterpoint to the dominant view of nurses' political inertia, suggesting that nurses are indeed involved in activism, but this aspect of their practice is highly contextualized and often invisible to decision makers and health

Table I. Participant Demographics.

\begin{tabular}{|c|c|}
\hline Variable & Statistics \\
\hline \multirow[t]{2}{*}{ Gender } & Female: 35 (87.5\%) \\
\hline & Male: 5 (12.5\%) \\
\hline \multirow[t]{4}{*}{ Generation } & Gen Y: 9 (22.5\%) \\
\hline & Gen X: 8 (20\%) \\
\hline & Boomer: 20 (50\%) \\
\hline & Overboomer: 3 (7.5\%) \\
\hline \multirow[t]{6}{*}{ Geographic area } & Greater Toronto area: 17 (42.5\%) \\
\hline & Central Eastern Ontario: 15 (37.5\%) \\
\hline & Central Western Ontario: 3 (7.5\%) \\
\hline & Hamilton Niagara: 2 (5\%) \\
\hline & Northern Ontario: 2 (5\%) \\
\hline & Eastern Ontario: I (2.5\%) \\
\hline \multirow{5}{*}{$\begin{array}{l}\text { Most current } \\
\text { practice } \\
\text { setting }\end{array}$} & Community or public health: 8 (20\%) \\
\hline & Education: 13 (32.5\%) \\
\hline & Hospital: 12 (32.5\%) \\
\hline & LTC: I (2.5\%) \\
\hline & Undergraduate student or not yet RN: 6 (I5\%) \\
\hline \multirow{5}{*}{$\begin{array}{l}\text { Highest level of } \\
\text { education }\end{array}$} & Diploma: 8 (20\%) \\
\hline & Baccalaureate in Nursing: 10 (25\%) \\
\hline & Masters: $12(32.5 \%)$ \\
\hline & PhD: $4(10 \%)$ \\
\hline & Undergraduate student or not yet RN: 6 (I5\%) \\
\hline
\end{tabular}

$\mathrm{RN}=$ registered nurse. professionals, and at times nurses themselves (FalkRafael \& Bradley, 2014; Giddings, 2005; MacDonnell, 2010). For nurses, like others in the female-dominated caring professions, the gendered division of labor (Armstrong \& Armstrong, 2004) and "gendered assumptions about nurses' [care]work ... serve to devalue care, in favor of a narrow biomedical notion of cure" (Choiniere, MacDonnell, \& Shamonda, 2010, p. 322). A critical feminist lens accounts for nurses' everyday activist work in both their personal and professional lives and can offer insight into how this political work can be marginalized (MacDonnell, 2010, 2011).

Vickers (1997) pointed out how women's political practice is often at local levels rather than state, provincial, or national legislative or electoral spheres, which have traditionally been marked as male dominated. MacDonnell's (2011) life history research on nurses' advocacy for lesbian health in Ontario shows how a critical feminist lens reveals complex dynamics that shape nurses' political knowledge, practices, and impacts. Her study uncovered nurses' subjugated knowledge and dynamics of gender, sexuality, and race that shape their fit within nursing. Similar life history findings (Giddings, 2005) about the marginalization of nurses who do not fit into the ideological construct of the White good nurse rarely emerge from nursing research, yet have important implications for nurses' ability to identify as nurses and practice within the profession.

Concerns about nursing recruitment and retention have prompted research on the three generations that comprise the current and emerging workforce in Canada: (a) Baby Boomers (referred to as Boomers) born between 1946 and 1964; (b) Generation X (referred to as Gen X), nurses, who were born between 1965 and 1978; and (c) Generation Y (referred to as Millennials or Gen Y), born between 1979 and 2000 (Hart, 2006). New graduates and current nursing students span all three generations and include internationally educated nurses as well as those who started their nursing career later in

Table 2. Student Participants by Program of Enrollment.

\begin{tabular}{lllll}
\hline $\begin{array}{l}\text { Student } \\
\text { Participants }\end{array}$ & Undergraduate & $\begin{array}{c}\text { MSc N } \\
\text { or NP }\end{array}$ & Doctorate & Total \\
\hline Gen Y & $\begin{array}{l}\text { Collaborative: } 5 \\
\text { Second entry: I }\end{array}$ & I & 0 & 8 \\
& Post RN: I & & & \\
Gen X & 0 & 2 & 0 & 2 \\
Boomer & Post RN: I & I & I & 4 \\
Overboomer & 0 & 0 & 0 & 0 \\
Total & 9 & 4 & 1 & 14 \\
\hline
\end{tabular}

$\mathrm{RN}=$ registered nurse; $\mathrm{MSc} N=$ master's nursing program; $N P=$ nurse practitioners. 
life (Canadian Nurses Association, 2008). Although they are by no means homogenous, members of each cohort share common characteristics related to work ethic, work styles, management preferences, and community service (Hart, 2006; Stuenkel, Cohen, \& de la Cuesta, 2005; Wieck, Prydun, \& Walsh, 2002).

Most generational studies of nurses used surveys to examine job satisfaction and engagement, workplace health, workload, recruitment, and retention with implications for organizations and policy makers (Blythe et al., 2008; Cho, Laschinger, \& Wong, 2006; Fitzgerald, 2007; Salt, Cummings, \& ProfettoMcGrath, 2008). None of these studies included a qualitative life history and critical feminist lens, nor have they focused on nursing activism. This is despite sociological studies that highlight Boomers' reputations as activists, with their roots in 1960s Civil Rights Movement and their midlife reflection, which prompts community work locally and globally (Kupperschmidt, 2001; Whittier, 1997; Williamson, 1998). Evidence abounds of young adults' civic and political engagement globally and their use of social media to develop networks and mobilize around political issues (Fraser, 2011; Kennelly, 2008; Kupperschmidt, 2001; McCaughey \& Ayers, 2003; Nelson, Joos, \& Wolfe, 2013). Beyond the assumed characteristics of these generations, we know little about nurses' engagement in political activism in different social or practice settings and how this relates to their careers and identities. This study fills that gap and explores how activism features in the career lives of four generations of Canadian RNs and nursing students.

\section{Methodology}

\section{Research Design}

We conducted a qualitative exploratory study. The three main research questions were as follows: (a) What factors influence nurses' activism? (b) How are gender and generation relevant to nursing activism? (c) What strategies are needed to support nurses' activist practices? In this study, meanings refer to personal, professional, and broader social understandings of nurses' activism. Practices refer to how nurses act individually and collectively to identify, challenge, or transform society. Impacts refer to outcomes of nurses' activist practices on nurses themselves, the profession, and broader society.

We used comparative life history methodology and a critical feminist lens to examine nurses' activism (MacDonnell, 2011). We defined activism as "a combination of individual and social action designed to gain political commitment, policy support, social acceptance, and system support for a particular health goal or programme" (World Health Organization, 1998, p. 5). We used Thompson's (2014) definition of social justice, which refers to interventions that ameliorate inequities in health that often require attention to the social determinants of health (p. E18).

Life history studies do not necessarily account for dynamics of power. Therefore, we used a critical feminist lens to bring attention to the ideologies that shape the social context of nurses' lives and power. Critical research theorists assume that knowledge and realities are socially constructed and shaped by power and historical, sociocultural, economic, and political contexts. Using the comparative life history approach with this critical feminist lens allowed us to examine patterns within individual narratives and across narratives, such as congruence with dominant social discourses and career scripts (Casey, 1992; MacDonnell, 2011). This approach facilitated our ability to focus on nurses' career lives, which, in contrast to most career research, encompasses meaningful life activities beyond the traditional boundaries of work (MacDonnell, 2011).

\section{Recruitment and Sampling}

We used purposeful convenience sampling to capture diversity of generation, type of activism, and practice setting. Working RNs and nursing students in the province of Ontario, Canada were recruited to join the study for a 1:1 telephone or in-person interview, or to be part of a focus group. From April, 2011 to June, 2013, notices were posted in various work and educational settings, such as university nursing listserves. We used flyers, union newsletters, and email distribution lists of professional and student organizations to recruit participants. An honorarium of a \$20 (Canadian) gift card for a coffee shop was offered. Interviews and focus groups were held in a place convenient for participants, such as a private room at a local university. Most participants opted for an individual interview. The potentially sensitive nature of the study may have influenced participants' preferences for the privacy of an interview. All willing participants were included. The study was approved by York University's Research Ethics Board prior to recruitment.

We recruited a total of 40 participants, in three waves, and interviewed them either individually or in focus groups. The first wave (April 2011 to October 2011) resulted in 11 individual interviews; nursing education experience was a common thread throughout many of the narratives. The participants' insights prompted a more focused examination of nursing education and activist experience from the perspective of students and educators.

Recruitment for this second wave occurred from October 2011 to May 2012. The study description on the original recruitment flyers was expanded to include the goal of "informing curriculum and creating supportive environments for activism." Flyers targeting students 
and educators were shared with postsecondary institutions. In this second wave, we enlisted 19 study participants, of whom 8 participated in individual interviews and 11 participated in one of four focus groups. Continuing analysis of the narratives revealed that institutional dynamics influenced activist practice for nurses in various settings, including nursing educators and nursing students. This prompted us to do another wave of recruitment to expand representation of nurse educators and students representing different nursing education roles and programs.

In the third wave, (May 2012 to June 2013), we recruited 10 participants, providing representation from more diverse nursing programs. For instance, we distributed the study through nursing student association networks and shared the study postings at nursing meetings and conferences that Ontario nursing educators often attend, requesting that they share the posting with their networks. Again, we continued to encourage potential participants to be part of focus groups, but all 10 participants from the final wave opted for individual interviews.

Forty participants in total were involved in either one of 29 interviews or four focus groups. Thirty-four were RNs whose lifetime work experience covered a diversity of settings, and six were undergraduate nursing students who were not yet practicing as RNs. Of the $34 \mathrm{RNs}, 26$ were nurse educators (see Tables 1 and 2). This was a predominantly female, white, middle-class, and well-educated sample of participants. We used highest educational achievement as a proxy for social class (Diemer, Mistry, Wadsworth, Lopez, \& Reimers, 2013). Among the participants who identified their ethnicity, 29 were Caucasian or from European descent; eight identified as members of other ethnic backgrounds, commonly Asian.

Of the 40 participants, three nurses were older than Boomers, whom we referred to as Overboomers. The generational breakdown of the sample, in which the number of Boomers and Overboomers was approximately twice that of either Gen X or Gen Y participants, was consistent with the demographics of the current nursing workforce in Ontario (Canadian Institute for Health Information, 2013). Given our aims for a sample with generational diversity, broad representation of nursing practice and activism, as well as particular attention to the educational context of activism, we decided to stop recruitment.

Interested participants contacted the research coordinator to arrange an interview and chose either a focus group or interview (face-to-face or by telephone). The study was explained to participants when they contacted the research coordinator, and written informed consent was obtained by fax or in person before the interview. With a potentially sensitive focus on work issues, the voluntary nature of the study was stressed. Participants could opt out at any time without negative consequences. After we obtained consent, participants completed a short demographic form either faxing it in with the consent form or answering these demographic questions at the beginning of the interview. Semistructured interviews and focus groups lasted 60 to 90 minutes and were audiotaped and transcribed. Questions addressed everyday political activities, factors affecting activism such as personal support, and generational issues.

\section{Data Analysis}

Audiotaped interviews and focus groups were transcribed. To protect confidentiality, participants' names were replaced with a code (e.g., Boomer (B\#18), Generation $\mathrm{X}$ (X\#9), Generation $\mathrm{Y}(\mathrm{Y} \# 6)$, or Overboomer (OB\#26). Steps were taken to ensure that no identifying participant or employer information was reported. We analyzed data using Qualitative Software Research NVivo10 to identify themes within and across narratives (MacDonnell, 2011). Data collection and analysis were iterative, so that during team debriefing of interviews, emerging issues and themes were noted. We modified the interview guide to highlight nursing education implications with later participants. Two researchers (J. M. and E. B. M.) examined the transcripts for themes and patterns and came to consensus regarding analysis. Data files were secured in a locked office, and computer files were password protected.

To ensure rigor, Lincoln and Guba's (1985) concept of trustworthiness was used. The research team took a reflexive stance to account for biases in designing the study and debriefed regularly after interviews and focus groups. Conscious reflection considered how researcher assumptions, biases, and experiences were influencing the emerging analysis. As nursing researchers who were insiders to issues of activism and education, this was important and took place through dialogue within the research team. We reported findings using extensive verbatim quotes in order to stay close to the data and provide a thick description to contextualize the findings. Preliminary and emerging findings were presented and discussed at conferences.

\section{Critical Influences on Nurses' Activist Practices}

The findings are reported to reflect the voices of participants across generations and are often contextualized by practice setting or type of activist practice. The first section reports on the range of nurses' activist practices; personal, professional, and societal factors influencing activism; and generational dynamics. The second section highlights contradictions in nurses' activist identities and practices, the impact of nursing activism, and supports that sustained this aspect of nursing practice. 


\section{Range of Nurses' Activist Practices}

Nurses contributed to policy at micro, meso, and macro levels (Saan \& Wise, 2011). Micro refers to nurses advocating on behalf of individuals or enabling them to take action on issues. Meso refers to action at the community or organizational level, and macro refers to action at the system level (Smith et al., 2008). Participants were involved as novice nurses, experienced nurses, or nursing students in activism across all three levels that included advocacy for improved workplace conditions, healthcare reform, and social determinants of health. At the micro level, nurses advocated for vulnerable groups through direct clinical care. Street health and community health centers, in particular, offered opportunities for activism in daily practice. Several participants spoke about creating conditions for others to advocate on emerging issues in response to community identified needs such as teen sexuality.

At the meso level, nurses were involved in unions and workplace committees to influence collective bargaining, health-care reform, and workplace violence. Administrators, often with rich experience across sectors, used their positional authority to publicly support health and safety legislation for practitioners and programs for marginalized groups.

At the macro level, nurses engaged in clinical best practice and policy development related to women abuse, homelessness, birth control, and food security that were considered part of nurses' professional roles or responsibilities. While most participants kept current with political issues online and signed petitions or advocated through their professional organizations, some participants were highly engaged in activism within the public domain, renowned for their leadership with professional and community organizations, or used social media extensively to collaborate across sectors and innovate in policy, professional practice, and delivery of clinical care.

\section{Personal, Professional, and Societal Factors Influencing Activism}

Diverse social and political factors sparked nurses' action on specific issues. Among them were experiences with unions, personal and professional mentors, education, family and community issues, and exposure to injustices such as workplace firing or social marginalization. B\#18 witnessed atrocities that shaped her understanding of one's social privilege and the need to support activities aligned with social justice. Another participant described the influence of the political environment on her activism:

I grew up in a time when there was much dissent in the U.S. ... that trio of assassinations in the U.S. in the " 60 s and into the " 70 s, so it was ... the time and the cauldron I grew up in. I was encouraged at home to have voice... encouraged professionally to have voice. (B\#14)

Education was identified as a critical influence on activism, especially among younger generations of nurses and nursing students. Undergraduate students pointed to politically focused coursework, involvement in student associations, and placements in community health or with the Registered Nurses Association of Ontario (RNAO) as key venues for political engagement and social change. A novice nurse's narrative showed that a solid foundation in critical social theory fostered an understanding of whose interests are met through activism and was integral to determining whether and how to "stick [their] neck out" (X\#9). She identified the importance of learning about policy windows and activist strategies such as writing policy briefs, while other students described becoming more aware of current events: "Since I've started the (undergraduate) program I've gotten more into $\mathrm{CBC}$ [Canadian Broadcasting Corporation] ...it's really applicable to us" (NSY\#1). (CBC is Canada's national public radio and television station.) Two Gen X participants spoke of having broader perspectives on understanding local and global injustices when taking community and global health courses because of their lived experiences of racialization. A graduate from a master's nursing program contrasted the focus of undergraduate education on "what's traditionally associated with activism" with graduate education's focus on "policy awareness...[nurses'] involvement in influencing and shaping policy" (Y\#19).

Many participants lauded RNAO's leadership on health and social policy issues dealing with delivery of care, such as nursing skill mix models, and structural changes required to address root causes of health inequities. RNAO's leadership provided nurses with varied opportunities to speak out collectively without personal or career risk. The RNAO also offered another layer of learning for nursing students beyond coursework. Y\#19 praised the RNAO for going beyond clinical practice and for what they "brought to the table" by advocating "for the marginalized...the minimum wage and why that was important to nursing." This highlighted the importance of nurses' involvement in social research as a form of advocacy to improve health.

Workplace issues, such as refusal of staff vacation time and nursing unit cutbacks, were antecedents for several Boomers' political action. B\#4, seeing little room to have an impact at work, shifted her attention to an upcoming election with its focus on health-care reform. Other participants addressed work issues head on, speaking up when patient care was compromised. In the words of $\mathrm{B} \# 12$, there was an incident that "opened my eyes and just had to push me forward to 
become active to do something about the safety, health and other issues... arising." The multitude of work issues offered many opportunities for nurses to engage politically. Some participants became engaged in highlevel health policy reform. As one participant explained:

Any job in nursing has been a very volatile, political area in the last 20 years. So in a way, I had no shortage of issues that have directly impacted my life... Working in them gives me a better ability to speak up and to organ ize around them. $(\mathrm{B} \# 22)$

\section{Generational Dynamics}

For the most part, Gen X and Gen Y narratives focused on social determinants of health and injustices for population groups using activist strategies such as rallies, online petitions, or letter-writing campaigns to build awareness about issues that affect health outcomes, such as poverty. Practice settings - especially in community health and its many programs, and coalitions - lent themselves to advocating for underserviced vulnerable groups. Y\#20 used Twitter or other social media strategically when sending information "to G8 members... about hunger... [and] concerns of people in their countries." She noted that "different platforms will not necessarily be received [well] by different... generations...." So she "tries to appeal to all generations ... e-mail... phone call... meetings" (Y\#20).

Boomers and Overboomers were more likely than Gen X or Gen Y to identify activism as a core practice and professional issue. Older nurses often expressed concern with recent trends in health system reform and the evolution of nursing as a profession. OB\#34 remarked, "I've been a nurse a long time and I've seen a lot of things taken away from nursing because we couldn't define who we are or what we are...we're not vocal enough." A nurse educator (B\#26) remarking on the changes to current practice that limit RNs' engagement, noted, "... we're losing our core here... A lot of the really important sources for our activism have to do with our engagement with people, with communities, with families." Many spoke of the value of clinical and organizational experiences for policy-related activism, especially during the mid 1990s when significant hospital restructuring began. As B\#22 said, "When the layoffs were happening in hospitals, I could talk about what that actually meant to nurses and patients."

Time and energy for political activities were identified across generations as barriers. Many older nurses identified workplace policies, hospital politics, and layers of management as constraints. One nurse stated that she had lost the joy of going to work because she felt she "couldn't make a difference" there. Another described the barriers and power imbalances that individuals and groups of nurses face:

If you're... an activist from a progressive point of view it's largely unpaid. Most organizations are under fun ded...you're fighting against very powerful interests [with] extreme resources ... you ... work extremely hard ... [it] takes... an emotional toll.... (B\#22)

\section{Contradictions Regarding Identities, Practices, and Impacts}

\section{Identities}

Participants across generations often held contradictory views on claiming an activist identity as a nurse. For example, B\#26 understood activism to be "essential to our moral survival... as people and as a profession." In contrast, X\#7 noted that "on the politics [sic] end of things if I want to say something and I say that I'm a nurse, that's a good thing; If I'm a nurse and I say I'm a political activist, that's a bad thing." Two nurses spoke of the contested nature of activism as a desirable attribute of nursing practice. One pointed to underlying assumptions that nurses must conform to an often unspoken stereotype of the nice caring nurse or good wife for whom "activism is seen as aggressive... unladylike" (OB\#25). Feminist principles challenge such gendered stereotypes affirming a broader understanding of who a nurse is and what the profession can be. As B\#29 said, "There... continues to be this uneasy relationship between nursing as perceived by whomever and feminism-It's never been two solitudes for me." $\mathrm{OB} \# 33$ agreed:

I think of myself as a nurse first and foremost and ... pol itical action and activism as a part of that role... It's always been part of my career... You can do it at vari ous levels including internally where you work with the internal politics ... or in your small community ... it's an important part of nursing ... nursing is political.

As another example, despite B\#5's community advocacy for special needs children, a skill she acquired in nursing, she noted, "I never saw myself as being an activist but I have been known as that for a couple years now." Such inconsistencies can affect one's perceived fit in nursing. For example, X\#11 stated that until her recent involvement in nurse practitioner networks, she saw no colleagues involved in activism. She shared that she felt "a little bit odd sometimes within my profession." Through the new networks, she found peers "interest[ed] in a more political realm, thinking more deeply about people's lives and how their nursing profession connects to that" (X\#11). 


\section{Practices}

Participants' narratives also reflect mixed messages that nurses receive about whether activism is appropriate in the practice setting at all. As B\#14, an experienced nurse leader, reflected:

There is an expectation it's part of the role, but frankly, it's not a role that we as a profession make any effort to enforce or regulate... if you go to the College of Nurses... search the standards...for advocacy, the word isn't there. So, regulation, as it's currently expressed, is a potential threat to the role of advocacy and activism on behalf of anything.

Not only did nurses at times discount their activist identities but also questioned whether their everyday work in a clinical or research context was indeed political activism. Others discounted the significance of their contributions in policy or transformative change, with little agreement on whether volunteer contributions through agency boards, community coalitions, and individual leadership to foster patient care and social justice could be counted as nursing activism. Yet participants consistently identified union and RNAO activities, protests, and letter writing as activism. According to X\#32, nurses do not understand the potential scope of their activism:

Nurses tend to see political activism at that national level...the "big P" Politics, and think "I could never ever do that," but they don't see that smaller level of "I can be the person who goes to my unit man ager... says this isn't appropriate"... who identifies issues around access or resources because I know this population or I know this clientele the best.

Many nurses affirmed the value of political activism for nurses and their communities. Y\#20 observed it's "like having this bird's eye view... has given me a powerful voice." X\#13 called it "a civic duty... to take responsibility for our lives and our community."

In addition to these contradictory messages, nurses acknowledged there may be mixed support for nursing activism. Several Boomers suggested that increasing corporatization of health care constrains nurses' ability to engage in workplace activism. They also questioned nurses' ability to be visibly political in the community, especially in public health, home care, or other settings where strict policies about engaging with media existed. Street health and community health centers were viewed as having fewer restrictions. B\#28 remarked, "Everybody is becoming more cautious because... public jobs have been under attack." B\#26 noted that while public health nurses have been known to be "politically savvy...structures in the organization...lack of space...time... have dampened their capacity to act politically." Nurses used phrases such as "We can't get our heads out of the corporate mindset" (B\#14), indicating that this has created a very different context for nursing over the last couple of decades. B\#40 stressed that nurses' social justice mandate in a practice landscape informed by the business model requires nurses to seriously consider the risks of activism and potential to take their profession "down the toilet."

... we've been at a pivotal time for a long time. There's a real danger that we could become less much less relevant if we are not better at staking out what is our area of practice and expertise... and activism has to be one of those, right?... Who else to better articulate those links between ... broad policies and human health? (B\#26)

Narratives reflected collective professional values and nurses' need to represent their profession well and support their collective body through "appropriate" political activities. Yet, our findings suggest that there is not consensus on what "appropriate" political activities entail.

\section{Impacts of Nurses' Political Activism on Nurses, the Profession, and Society}

A number of Boomers and Overboomers focused on union or workplace activism and described activism with the RNAO that was personally satisfying and had widespread impact. They also shared examples of unsettling dynamics related to publicly taking a stand on a political issue or reluctantly opting to remain silent because of career risks, such as not getting tenure. One Boomer identified a traumatic experience at work that led her to engage in activism: "I think my eyes got opened to being, I suppose an activist, or more outspoken...because I felt...wronged" (B\#12). Two nurses spoke of being arrested earlier in their careers for civil disobedience on issues of civil and reproductive rights. Several others described participation in more recent protests like the Occupy Movement. Engagement in such activities had to be weighed against potential career and job costs. A primary theme threaded throughout the narratives was avoiding job and career consequences as described by B\#22, who opted not to participate in a political protest: "I considered joining them but some of them actually got arrested... don't want to put myself in that type of a situation." Others, notably older nurses, thrived on uncertainty and career risks, finding many occasions from early in their nursing careers to act confidently and visibly to advocate on health and social concerns.

Union-related activity, identified by some as the one legitimate way to engage politically in nursing, was 
unevenly supported and posed career risks. OB\#25 noted that while it is rarely discussed in nursing curriculum, union activism is an important legacy for nursing in Canada. Despite identifying this crucial vehicle of nursing activism, even she referred to going on a union-led strike as a delicate thing because of the possibility of hurting patients. Tensions in the narratives were evident as another Boomer noted that union work is often marginalized compared with work done with other professional bodies.

Several nurses described the job risks linked to union activism. While involved in union picketing, some nurses had received clear messages from their employers that they had "better calm it down." One nurse (B\#31) described an intimidating police presence at a union's picketing activities. Another participant shared details of being fired in relation to union activity and how that was eventually successfully grieved. This career risk was reflected in OB\#34's story asking her manager friend to review her resume when job seeking in the 1980s: "I had written ... that I was a union rep ... being very proud [of it]... She said 'You better take that off your resume because you will not get a job." When $\mathrm{OB} \# 34$ was asked by an interviewer for this study if she thought it would be the same today, she responded, "Yes, I do...I was in management...there is tension with unions.... I would probably caution someone to word it in a different way, to talk about leadership."

The life histories clearly revealed the unexpected nature of nurses' involvement, as they were swept into situations that left them with few options other than to take action on some level. Several Boomers shared painful stories of "standing up for issues" that related to workplace health and safety, workplace conflict and patient care, illness, injury and disability, the negative impacts of cost-cutting on nurses' practice settings, and concern for the future of the profession for RNs.

More than one participant detailed workplace experiences that shattered their faith in existing legal, professional, and union support systems, despite "all we did was... our job at work and then... [we were] attacked" (B\#12). They described working strategically inside and outside of professional and organizational structures to continue their nursing careers. An educator (B\#40) underscored the need for nurses to realize that critical consequences can ensue from political activism: "I use myself as a role model with ... students ... I tell them all the things that have happened to me, where I got in serious trouble, and I say ... until you graduate do not be an advocate." The following Boomer's (B\#12) statement reflects the intense effect of these experiences:

... years later, and I mean now I can talk about it and it doesn't bother me. But there are times, and it's like a death... The stress level was right up there close to a death. The grief and the pain of going through that whole experience was right up there.

A number of older nurses considered the historical and economic contexts of cost cutting in the 1990s with widespread restructuring and loss of nursing jobs as integral to understanding their activist work. As B\#26 stated, "After years of lacking the sort of support to get joy and satisfaction from our profession ... activism is probably the last thing on their minds." The emotional work of activism and the personal, health, and career costs of challenging the system were evident in a number of Boomer and Overboomer narratives.

Job loss from front line or managerial positions that resulted from openly speaking out to challenge the system was the reality for a number of participants, even those whose careers on the surface were a "success." B\#6 reflected: "Emotionally, we are human beings... influenced by...stories patients tell...the dilemmas that you face, ethical issues, economic issues that face you like...layoffs on the horizon." Several Boomers were chastised by directors or managers for going against their agenda "... because you're going to advance causes that they don't want to hear about" (B\#3). B\#2 contrasted her meaningful work on a community board with experiences in her workplace where young managers with limited experience stifled creative problem solving or strategies to move issues forward. As a result, experienced staff nurses felt undervalued. She shared: "On paper it looks wonderful. You can be a part of all these committees, [but] everything seems to stagnate" (B\#2). The barriers faced by some nurses while engaging in activism created consequences that ranged from disillusionment to negative health outcomes. After years of feeling respected for her nursing contributions, B\#8 described her fear of "a negative evaluation" and work-related stress that required medical attention after she was silenced for taking a stance.

Honestly, I couldn't believe what was going on ... [I] had involvement with the College [of Nurses],...CNA [national body],... best practice guidelines then being called a bully... Yeah, it was hard on me... I wasn't quite certain what people were thinking.

In contrast, younger nurses' experiences of activism were rarely associated with negative consequences. As X\#11 said,

It's affected my health positively ... because of connec tions with... like minded people... a sense of following through on thoughts and feelings about issues... being able to research them and then do something about it.

Disappointment or frustration marked some narratives due to the challenges of motivating peers: "You feel so 
passionate about something and other[s] might not" (Y\#20).

\section{Personal, Professional, and Organizational Supports}

Many participants agreed on the importance of having support systems in place in order to meaningfully and effectively take action on issues. OB\#33 stressed:

If you're going to be known as an activist you really have to have a strong ego and a strong support system. Otherwise it's really hard ... there's always consequences for standing up...I've had my house picketed... had people tell my kids they should be ashamed of me... and my husband should control me and all those kinds of things.

Key influencers who sparked nurses' initial political engagement included union leaders, politicians, family, and colleagues, some of whom were "radical feminists and very confident" (B\#29). Role models, professional organizations, and unions provided crucial, ongoing support for others to develop skills and expand involvement. B\#10 spoke about her nurse manager:

It was a blessing in my career to have that kind of lead ership up front... Many times when I went to her... she would say, 'Okay, this is what you need to do'... She had the...connections to know.

Working in a management role, OB\#33 indicated, "I created a lot of trouble... uphill battles all of them." She stressed how her work was often underpinned by well-established professional and community networks and high-level administrative support, all critical for positive change. Finding colleagues and mentors "to get your back" (B\#6) was deemed integral to nurses' survival and even decisions to continue working in the profession. Given their perceptions that younger nurses will more easily leave a workplace or the profession for greener pastures than loyal older nurses, some participants advocated for unions to engage younger nurses.

Nurses are transforming their communities and systems of care despite the often demanding nature of activism, competing work and life priorities, and barriers to everyday political involvement. As OB\#33 shared, "It's a big risk doing advocacy work... You can get into some trouble...fired... shunned." Yet, she stressed that the impacts have ongoing ripple effects on communities and systems of care and transform nursing itself:

I think you change the direction of nursing when you do that type of work. You make it more caring and you broaden it... You're not just looking after this one [issue]...the change there affects whatever happens further out from you... You've done amazing things, but you don't know where...(OB\#33)

These narratives point to factors, including gendered norms, which shape contradictory meanings of identities, practices, and impacts of nursing activism. Activism was often prompted by critical incidents and influences - including organizational dynamics, supports, and mentors - thus shaping participants' activism and the transformative potential of nursing.

\section{Discussion}

These study findings show that despite the contradictions in how nurses understand and enact their activist roles, many nurses and nursing students in Ontario are engaged in activist practice in both their personal and professional domains. There are implications for nursing practice, education, and research.

\section{Implications for Nursing Practice}

Nurses across generations in this study engaged in diverse practices that were aligned with civic and social activism and values of empowerment, self determination, social determinants of health, and emancipatory goals of social justice and structural change (Falk-Rafael, 2005; Norris, 2002; Saan $\&$ Wise, 2011). In doing so, they promoted health at the micro, meso, and macro levels to transform communities and systems. However, factors such as organizational barriers, professional norms, as well as the political landscape affected their ability to take action (Hamilton \& Campbell, 2012; MacDonnell, 2010). Nurses in Canada take action on issues such as climate change, health-care reform, and refugee, Aboriginal, and LGBTQ rights. Canada's new Prime Minister, Justin Trudeau, considered a progressive leader who is committed to gender equality, helps to create a political climate that is conducive to such activism (Hepburn, 2016; Smith, 2016). Canadian nurses have opportunities for collective political activism in some provinces such as Ontario through RNAO and their unions, as well as through the Canadian Nursing Association.

Potential venues for activism vary within Canada and among other national or regional contexts. Because our findings showed that organizational support also varies considerably, there are implications for building the capacities of nurses to engage in political activism through new types of supports. These might include mentorship or creating spaces for dialogue on political action in professional workshops that build on existing professional resources (RNAO, 2015) and are informed by research about nurses' political action experiences. 


\section{Implications for Nursing Education}

Nurses and nursing students in Ontario expressed diverse perspectives regarding the importance of political nursing practice, and how political activism was addressed in nursing curriculum. Our study's findings align with other nursing research that calls for a reorientation of nursing and development of nursing practice and professional activities. This reorientation would specify that political action to improve the lives of people, nurses, and systems is indeed caring practice and thus an integral part of nurses' professional practice (Akhtar-Danesh et al., 2013; Apesoa-Varano \& Varano, 2004; FalkRafael \& Betker, 2012; Kagan, Smith, \& Chinn, 2014; MacDonnell, 2009, 2010, Thompson, 2014).

\section{Implications for Nursing Research}

Accounting for gender and other aspects of power is integral to understanding how activism features in the career lives of nurses. The findings reveal the limitations of a narrow view of political action, thus challenging the conventional discourse of nurses' political inertia (Boswell, Cannon, \& Miller, 2005; MacDonnell, 2010; Spenceley et al., 2006; Vickers, 1997). Using a life history approach with a critical feminist lens brings to light nurses' commitments to identifying and acting on injustices, how pivotal incidents drove their activist practice, and dynamics that render invisible or marginal some of nurses' daily contributions to care (Hamilton \& Campbell, 2012; MacDonnell, 2011). This approach challenges the dominant view that is the tendency to individualize experiences or perceptions. Rather, it points to patterns in nurses' career lives that reflect social and structural dynamics of power.

Other literature points to job risk for activist nurses who hold precarious nursing work, who are racialized, and activists with disabilities (Apesoa-Varano \& Varano, 2004; Giddings, 2005; MacDonnell, 2007; Oliver \& Barnes, 2012). In an era when nursing work is increasingly precarious, further life history research is needed. This research could shed light on how race, class, gender, sexuality, and positional authority of individual political actors shape their experience of political activism (Apesoa-Varano \& Varano, 2004; Falk-Rafael \& Bradley, 2014; Giddings, 2005; MacDonnell, 2010). Further research is needed that uses a range of methodologies, including mixed methods approaches that use probability sampling to provide a diverse sample, to expand on the generational, social, and political contexts of nursing activism for nurses and nursing students in Canada and in an international context.

\section{Study Limitations}

Limitations of this study include the self-selected nature of the participant sample and the recruitment strategy. We originally aimed for mixed and generational specific focus groups, but we faced challenges with recruitment, especially for focus groups. Participants who expressed interest may have been involved with the union, professional, and academic organizations that posted the study information, leading to a sample with relatively high social privilege. Participants recruited through other networks may have provided a more diverse sample of nurses and nursing students, resulting in different findings. The purposeful, convenience sample had a large proportion of nursing educators and students which may have affected the findings. While the small sample represented nurses who practiced in diverse work settings from both rural and urban Ontario, our findings are not generalizable to nursing in the rest of Canada or beyond. The sample was also too small to examine differences between male and female participants' experiences or to draw conclusions about cohorts or different generations of nurses. Generational analysis of Canadian nursing practice is challenging because age, professional experience, and nursing education confound findings that could be linked to age (Blythe et al., 2008). With a variety of nursing education programs in Ontario, mature, internationally educated, and students in their late teens are all involved in undergraduate programs. Age and years of nursing experience since graduation likely also affect findings. A number of Gen Y participants were nursing students with no experience practicing as RNs. While younger participants offered important insights into critical factors affecting activist practice, it is possible their more positive experiences of activism and absence of negative consequences reflect their shorter time spent in the workforce and the small self-selected sample.

This study unexpectedly took 4 years to complete. Data collection from all but one participant occurred from April 2011 to June 2013. This final interview was postponed because the participant was ill, but we agreed to extend the data collection to accommodate the participant who became available in June 2015. At this point, we were still analyzing data and had obtained ethics approval to extend the data collection period. Doing this study over 4 years limits the study findings in that this study represents snapshots of nurses' stories of their lives. The social and political context in which nurses engage in political activism can change during this time.

\section{Conclusion}

We examined the life histories of four generations of nurses in Ontario. More salient than generation in accounting for variation in nurses' and nursing students' narratives were factors related to career and work experiences that prompted activism, as well as personal and professional supports that were available to them. Our results illustrated how gendered norms and professional 
and organizational dynamics shape contradictory nursing activist identities, practices, and impacts, as well as the personal and professional environments in which nurses and nursing students engage in political activism. Our findings point to the need for further research on nursing activism that accounts for the situated experiences of diverse groups of nurses and explores the various issues on which they take action. This research is needed to better support nurses across settings and to align the evolution of the profession with social justice goals.

\section{Acknowledgments}

We gratefully acknowledge funding from the Social Sciences and Humanities Research Council of Canada and thank the participants who shared their wisdom and experiences. We offer our thanks for the contributions of research assistants on this project: Charlotte Rowell, MA, Anne Vongprachanh, BScN MBA, MScN, Beth Siurna, RN, MEd, MN, Penny Dowedoff, MA PhD(c). We appreciated Ilo Katryn Maimets' assistance with this manuscript. Earlier versions of this paper were presented at the Canadian Association of Schools of Nursing (CASN) Research Conference in Toronto, Ontario, May, 2012; the Community Health Nurses of Canada Conference in Ottawa, Ontario, June, 2014; and CASN Nursing Education Conference in Halifax, Nova Scotia, May of 2014.

\section{Declaration of Conflicting Interests}

The feminist declared no potential conflicts of interest with respect to the research, authorship, and/or publication of this article.

\section{Funding}

The author(s) disclosed receipt of the following financial sup port for the research, authorship, and/or publication of this article: This research was funded by the Social Sciences and Humanities Research Council of Canada.

\section{References}

Akhtar Danesh, N., Baumann, A., Kolotylo, C., Lawlor, Y., Tompkins, C., \& Le, R. (2013). Perceptions of profession alism among nursing faculty and nursing students. Western Journal of Nursing Research, 35, 248 271. doi:10.1177/ 0193945911408623.

Apesoa Varano, E. C., \& Varano, C. S. (2004). Nurses and labor activism in the United States: The role of class, gender, and ideology. Social Justice, 31, 77104.

Armstrong, P., \& Armstrong, H. (2004). Thinking it through: Women's work and caring in the new millenium. In K. R. Grant, C. Amaratunga, P. Armstrong, M. Boscoe, A. Pederson \& K. Willson (Eds.), Caring for caring about (pp. 5 43). Aurora, ON: Garamond Press.

Avolio, C. D. (2014). Political advocacy: Beliefs and practices of nurses (Unpublished thesis). University of Windsor, Ontario, Canada.

Blythe, J., Baumann, A., Zeytinoglu, I. U., Denton, M., Akhtar Danesh, N., Davies, S., \& Kolotylo, C. (2008). Nursing generations in the contemporary workplace. Public Personnel Management, 37(2), 137 159. doi:10.1177/0091 02600803700201.

Boswell, C., Cannon, S., \& Miller, J. (2005). Nurses' political involvement: Responsibility versus privilege. Journal of Professional Nursing, 21(1), 5 8. doi:10.1016/j.profnurs. 2004.11.005.

Canadian Institute for Health Information. (2013). Regulated nurses: Canadian trends, 2007 2011. Retrieved from https://secure.cihi.ca/free_products/Regulated Nurses_EN.pdf.

Canadian Nurses Association. (2005). Primary health care: A summary of the issues. Ottawa, Canada: Author. Retrieved from https://www.cna aiic.ca/ /media/cna/page content/pdf en/bg7_primary_health_care_e.pdf?la en.

Canadian Nurses Association. (2008). Nursing education in Canada statistics: 2006 7. Ottawa, Canada: Author. https:// www.cna aiic.ca/ /media/cna/page content/pdf en/educa tion_statistics_report_2006_2007_e.pdf.

Carnegie, E., \& Kiger, A. (2009). Being and doing politics: An outdated model or 21 st century reality? Journal of Advanced Nursing, 65(9), 1976 1984. doi:10.1111/j.1365 2648.2009. 05084.x.

Casey, K. (1992). Why do progressive women activists leave teaching? Theory, methodology and politics in life history research. In I. F. Goodson (Ed.), Studying teachers' lives (pp. 187 208). New York, NY: Teachers College, Columbia University. doi:10.4324/9780203415177_chapter_7.

Cho, J., Laschinger, H. K. S., \& Wong, C. (2006). Workplace empowerment, work engagement and organizational com mitment of new graduate nurses. Nursing Leadership, 3, 43 60. doi:10.12927/cjnl.2006.18368.

Choiniere, J. A., MacDonnell, J., \& Shamonda, H. (2010). Walking the talk: Insights into dynamics of race and gender for nurses. Policy, Politics and Nursing Practice, 11(4), 317 325. doi:10.1177/1527154410396222.

Community Health Nurses of Canada. (2011). Canadian com munity health nursing: Professional practice model \& stand ards of practice. St. Johns, Canada: Author. Retrieved from https://www.chnc.ca/en/standards of practice.

D’Antonio, P., Connolly, C., Mann Wall, B., Whelan, J. C., \& Fairman, J. (2010). Histories of nursing: The power and the possibilities. Nursing Outlook, 58, 207 213. doi:10.1016/ j.outlook.2010.04.005.

Diemer, M. A., Mistry, R. S., Wadsworth, M. E., Lopez, I., \& Reimers, F. (2013). Best practices in conceptualizing and measuring social class in psychological research. Analyses of Social Issues and Public Policy, 13(1), 77113. doi:10.1111/asap.12001.

Falk Rafael, A., \& Betker, C. (2012). The primacy of relation ships: A study of public health nursing practice from a crit ical caring perspective. Advances in Nursing Science, 35(4), 315 332. doi:10.1097/ans.0b013e318271d127.

Falk Rafael, A. R. (2005). Speaking truth to power: Nursing's legacy and moral imperative. Advances in Nursing Science, 28(3), 212 223. doi:10.1097/00012272 20050700000004.

Falk Rafael, A. R., \& Bradley, P. A. (2014). "Towards Justice in Health": An exemplar of speaking truth to power. Advances in Nursing Science, 37(3), 224 234. doi:10.1097/ ans.0000000000000034. 
Fitzgerald, D. C. (2007). Aging, experienced nurses: Their value and needs. Contemporary Nurse, 24(2), 237242. doi:10.5172/conu.2007.24.2.237.

Fraser, R. (2011). The nurses social media advantage: How making connections and sharing ideas can enhance your nur sing practice. Indianapolis, IN: Sigma Theta Tau International.

Giddings, L. S. (2005). Health disparities, social injustice, and the culture of nursing. Nursing Research, 54(5), 304312.

Government of Canada. (2016). Canada's health care system. Retrieved from http://healthycanadians.gc.ca/health system systeme sante/system systeme/about apropos eng.php.

Hamilton, P., \& Campbell, M. (2012). Knowledge for reform ing nursing's future: Standpoint makes a difference. Advances in Nursing Science, 34(4), 280 296. doi:10.1097/ ans.0b013e3182356b6a.

Hart, S. M. (2006). Generational diversity: Impact on recruit ment and retention of registered nurses. Journal of Nursing Administration, $\quad 36(1), \quad 1012 . \quad$ doi:10.1097/00005110 20060100000004.

Hepburn, B. (2016, October 13). Why Trudeau rates A after year 1. The Toronto Star. Retrieved from https://www.thes tar.com/opinion/2016/10/13/why trudeau rates a after year 1 hepburn.html.

Kagan, P. N., Smith, M. C., \& Chinn, P. L. (Eds.). (2014). Philosophies and practices of emancipatory nursing: Social justice as praxis. New York, NY: Routledge.

Kennelly, J. (2008). Citizen youth: Culture, activism, and agency in an era of globalization (Unpublished doctoral thesis). University of British Columbia, Vancouver, Canada.

Kupperschmidt, B. R. (2001). Understanding net generation employees. Journal of Nursing Administration, 31(12), 570 574. doi:10.1097/00005110 20011200000007.

Lincoln, Y. S., \& Guba, E. G. (1985). Naturalistic inquiry. Newbury Park, CA: Sage Publications.

MacDonnell, J. (2010). Policy talk: Gender and the regulation of nursing knowledges and practices. Advances in Nursing Science, 33(3), 219 233. doi:10.1097/ans.0b013e3181eb4215.

MacDonnell, J. A. (2007). Comparative life histories of nurses who advocate for lesbian health in a Canadian context: Sexual orientation as a factor in career and workplace dynamics. In M. V. L. Badgett \& J. Frank (Eds.), Sexual orientation discrimination: An international perspective (pp. 118 135). London, England: Routledge.

MacDonnell, J. A. (2009). Fostering nurses' political know ledges and practices: Education and political activation in relation to lesbian health. Advances in Nursing Science, 32(2), 158 172. doi:10.1097/ans.0b013e3181a3ddd9.

MacDonnell, J. A. (2011). Gender, sexuality and the participa tory dimensions of a comparative life history policy study. Nursing Inquiry, 18(4), 313 324. doi:10.1111/j.1440 1800.2011.00524.x.

McCaughey, M., \& Ayers, M. D. (Eds.). (2003). Cyberactivism: Online activism in theory and practice. New York, NY: Routledge.

Montalvo, W. (2015). Political skill and its relevance to nursing: An integrative review. Journal of Nursing Administration, 45(7/8), 377 383. doi:10.1097/nna.0000000000000218.
Nelson, R., Joos, I., \& Wolfe, D. (2013). Social media for nurses: Educating practitioners and patients in a wired world. New York, NY: Springer.

Norris, P. (2002, August). Democratic phoenix: Agencies, rep ertoires, \& targets of political activism. Paper presented to the Annual Meeting of the American Political Science Association, Boston, MA.

Oliver, M., \& Barnes, C. (2012). The new politics of disablement. New York, NY: Palgrave McMillan.

Registered Nurses Association of Ontario. (2015). Taking action: Becoming politically involved. Toronto, Canada: Author. Retrieved from http://rnao.ca/sites/rnao ca/files/ Taking_Action_Political_Action_Toolkit_Final_0.pdf.

Saan, H., \& Wise, M. (2011). Enable, mediate, and advocate. Health Promotion International, 26(S2), iil87ii 193. doi:10.1093/heapro/dar069.

Salt, J., Cummings, G. G., \& Profetto McGrath, J. (2008). Increasing retention of new graduate nurses: A systematic review of interventions by healthcare organizations. Journal of Nursing Administration, 38(6), 287 296. doi:10.1097/ 01.nna.0000312788.88093.2e.

Smith, D., Jacobson, L., \& Yiu, L. (2008). Primary health care. In L. L. Stamler \& L. Yiu (Eds.), Community health nursing: A Canadian perspective (2nd ed., pp. 111 124). Toronto, Canada: Pearson Prentice Hall.

Smith, J. (2016, November 22). Trudeau to discuss LGBTQ rights at la Francophonie summit in Madagascar. The Toronto Star. Retrieved from https:/www.thestar.com/ news/canada/2016/11/22/trudeau to discuss lgbtq rights at la francophonie summit in madagascar.html.

Spenceley, S. M., Reutter, L., \& Allen, M. N. (2006). The road less traveled: Nursing advocacy at the policy level. Policy, Politics and Nursing Practice, 7(3), 180 194. doi:10.1177/ 1527154406293683.

Stuenkel, D. L., Cohen, J., \& de la Cuesta, K. (2005). The multigenerational nursing work force. Journal of Nursing Administration, 35(6), 283 285. doi:10.1097/000051102005 0600000003.

Thompson, J. L. (2014). Discourses of social justice: Examining the ethics of democratic professionalism in nursing. Advances in Nursing Science, 37(3), E17 E34. doi:10.1097/ ans.0000000000000045.

Vandenhouten, C. L., Malakar, C. L., Kubsch, S., Block, D. E., \& Gallagher Lepak, S. (2011). Political participation of registered nurses. Policy, Politics, \& Nursing Practice, 12(3), 159 167. doi:10.1177/1527154411425189.

Vickers, J. (1997). Reinventing political science: A feminist approach. Halifax, Canada: Fernwood Publishing.

Whittier, N. (1997). Political generations, micro cohorts, and the transformation of social movements. American Sociological Review, 62, 760 778. doi:10.2307/2657359.

Wieck, K. L., Prydun, M., \& Walsh, T. (2002). What the emerging workforce wants in its leaders. Journal of Nursing Scholarship, 34(3), 283 288. doi:10.1111/j.1547 5069.2002.00283.x.

Williamson, J. (1998). Political activism and the aging of the baby boom. Generations, 22(1), 5559.

World Health Organization. (1998). Health promotion glossary. Health Education and Health Promotion Unit. Geneva, Switzerland. Retrieved from http://www.who.int/healthpro motion/about/HPR\%20Glossary\%201998.pdf?ua 1. 
World Health Organization and the Canadian Public Health Association. Ottawa charter for health promotion. Canadian Journal of Public Health, 77(6), 425.

\section{Author Biographies}

Judith A. MacDonnell is an associate professor in the School of Nursing at York University, Toronto, Ontario, Canada.
Ellen Buck-McFadyen is a doctoral student in nursing at McMaster University, Hamilton, Ontario and faculty at the Trent University School of Nursing in Peterborough, Ontario, Canada. 